\title{
A EXPERIÊNCIA DO OP CAMPINAS: QUESTÕES REFERENTES AO ESTADO E À SOCIEDADE CIVIL
}

José Braga ${ }^{1}$

\section{RESUMO}

O artigo busca apresentar a experiência do Orçamento Participativo - OP Campinas, levantando questões relacionadas à relação do OP com as dinâmicas do Estado e da sociedade civil. A proposta é discorrer sobre a democratização do Estado e da sociedade civil debatendo com variáveis que perpassaram a experiência. Ainda contribuir com o debate da democratização do nosso território.

PALAVRAS-CHAVE: Democracia; Estado; Sociedade Civil.

\section{1) INTRODUÇÃO}

“A democracia participativa é condição fundamental para o ato de governar em nosso projeto democrático-popular”. Estas palavras abrem o Programa de Governo que norteou os trabalhos do programa do Orçamento Participativo - OP Campinas.

As experiências de OP têm demonstrado ser este um importante instrumento de democratização da relação do Estado com a sociedade civil. Mais que isto, o OP pode ser instrumento na disputa com o modelo político-econômico neoliberal, na medida que pode inverter a ordem dos gastos públicos, priorizando interesses coletivos, e ampliando, muitas vezes, as áreas de atuação do Estado, ao contrario de priorizar o pagamento de dívidas e o atendimento de interesses de pequenos grupos.

No quarto ano do governo que iniciou a experiência de construir o orçamento da cidade com a participação direta da população, este texto tem o objetivo de identificar que caminhos trilhamos; socializar e registrar a experiência e avançar algumas reflexões sobre esta. Para tanto, iniciamos fazendo uma revisão bibliográfica que nos ajuda localizar

\footnotetext{
${ }^{1}$ Economista, Coordenador da Participação Popular e do Orçamento Participativo do Governo Democrático e Popular (2001/4) de Campinas / São Paulo / Brasil. E-mail: rrbraga@uol.com.br

\begin{tabular}{llllll}
\hline Serviço Social \& Saúde & Campinas & v. 4 & n. 4 & p. 1-156 & Maio 2005
\end{tabular}
} 
algumas questões importantes à apropriação da experiência ${ }^{2}$, para, em seguida, fazermos uma apresentação e uma primeira avaliação, dialogando com questões referentes ao Estado e à sociedade civil.

Pretendemos apresentar e discutir aspectos da experiência inicialmente apresentando a metodologia que orientou os trabalhos nos três primeiros anos ${ }^{3}$. Em seguida, discutiremos questões relacionadas à sociedade civil e sua relação com o OP a partir da intensidade e da dinâmica da sua participação nos diferentes momentos do ciclo. Discutiremos a relação do OP com o Estado a partir da dinâmica orçamentária, da relação com a burocracia, e, por ultimo, apresentando alguns resultados na alocação dos recursos públicos.

Nosso propósito é demonstrar aspectos da contribuição do OP para o debate da democratização do Estado e da sociedade civil.

\section{2) ESTADO, MERCADO E DEMOCRACIA}

Décio Saes em “O Conceito de Estado Burguês” (1994) busca demonstrar que a construção do conceito só pode ser empreendida no quadro da problemática teórica dos tipos de Estado correspondentes aos tipos diversos de relações de produção. A base para o desenvolvimento desta problemática estaria nas obras de Marx, Engels e Lênin, e, segundo o autor, consistiria num conceito de Estado válido para todas as sociedades divididas em classes, onde o Estado seria a organização especializada na função de moderar a luta entre as classes antagônicas, garantindo a conservação da dominação de classe. Neste sentido o Estado burguês seria aquele que torna possível a reprodução das relações de produção capitalista. Contudo “a correspondência entre o Estado burguês e as relações de produção

\footnotetext{
${ }^{2}$ Lembramos que o objetivo do texto não é esgotar ou fazer uma avaliação integral da experiência, mas, apenas apontar e discutir algumas questões que perpassaram a experiência, portanto, não serão tratadas todas as questões que a bibliográfica inicial levanta.

${ }^{3}$ Em Campinas a metodologia é anualmente avaliada pelo COP e pelo Governo através da Coordenadoria Especial da Participação Popular e do Orçamento Participativo que é ligada ao gabinete da prefeita. As alterações nos três primeiros anos foram no sentido de permitir a participação do movimento HIP HOP, setores da economia como os produtores rurais as micros e pequenas empresas, as cooperativas e a economia informal e ampliar temas como a cultura e a habitação, sem alterar o ciclo anual, o que aconteceu na metodologia trabalhada em 2004.

Serviço Social \& Saúde Campinas

v. 4 n. 4 p. $1-156$

Maio 2005
} 
capitalista não consiste numa relação causal simples e unívoca entre ambos” (SAES, p. 21). Portanto, segundo o autor, o Estado pode ser qualificado como capitalista quando cria as condições ideológicas necessárias à reprodução das relações de produção capitalista, e o Estado burguês, o faria, desempenhando dupla função: a) individualizando os agentes da produção (produtores direito e proprietários dos meios de produção), mediante a sua conversão em pessoas jurídicas, portadoras de direitos individuais que estabelecendo contratos que conferem troca desigual entre o uso da força de trabalho e o salário na compra e venda da força de trabalho dos produtores direitos. b) A segunda função do Estado burguês seria neutralizar a tendência de ação coletiva dos produtores diretos decorrente do caráter socializado do processo de trabalho.

Se na primeira função o Estado burguês coloca o produtor direto no mercado de trabalho como sujeito individual dotado de vontade e de direito, na segunda, neutraliza, no produtor direito, a tendência à ação coletiva organizando um outro coletivo, o Povo-Nação, ou seja, torna os produtores diretos e os proprietários dos meios de produção um único coletivo com interesses comuns dentro de um espaço geográfico delimitado, o território. Neste sentido a burocracia do Estado burguês se apresenta como o representante do PovoNação, na medida em que se apresenta como o agente de concretização do interesse geral de todos os indivíduos. Contudo o desenvolvimento da luta de classe pode determinar outras formas de representação política que não a burocrática, na medida que esta não se apóia em nenhuma mediação para se apresentar como representante do Povo-Nação, é a sua própria estrutura, não a presença de mecanismos de consulta à vontade popular, que a define como tal. Já as formas de representação propriamente políticas apóiam-se em mecanismos de consulta à vontade popular e "a sua existência contribui, portanto, para que se difunda a idéia de que a consulta política é condição essencial da concretização do interesse geral da sociedade" (SAES, p. 47).

Segundo Atílio Boron (2004) a amplitude e a profundidade das mudanças experimentadas na segunda metade do século XX situariam nossa época como uma das mais dinâmicas e revolucionárias. Nas suas palavras, “a profunda reestruturação econômica e social propiciada desde a crise do keynesianismo - em meados da década de 70 - e o auge das idéias neoliberais, assistimos a uma expansão dos mercados sem \begin{tabular}{llllll}
\hline Serviço Social \& Saúde & Campinas & v. 4 & n. 4 & p. 1-156 & Maio 2005
\end{tabular} 
precedentes na história do capitalismo. O resultado desta inédita mercantilização da vida social foi um notável desequilíbrio na relação entre mercado, Estado e sociedade” (BORON, p. 18). As empresas transnacionais e as gigantescas firmas que dominam os mercados teriam se transformado em protagonistas privilegiados nas “débeis democracias". "Seu domínio na segunda arena da política democrática, os mercados, projeta-se decisivamente na esfera pública e nos mecanismos decisórios de Estado” (BORON, p. 45). Segundo o autor esta realidade "levanta um problema crucial para a teoria democrática: como contrabalançar a exorbitante gravitação destes atores, que corrói até a raiz a credibilidade do processo democrático? Quais são as instituições, normas ou instrumentos idôneos para exercer um controle democrático sobre estas gigantescas burocracias privadas ou públicas?” (BORON, p. 44)

Göran Therborn (2004) aponta quatro questões que considera fundamental para o debate das teorias do Estado e seus desafios na atual situação política: (i) o Estado nação frente aos processos de globalização, (ii) a questão da eficiência relativa do Estado, (iii) as políticas de identidade, e (iv) a ênfase na importância da sociedade civil.

A questão do Estado-nação frente aos processos de globalização refere-se a mudanças na relação do Estado com o mercado em detrimento do primeiro. Contudo tais mudanças não teriam inviabilizado o Estado e o conjunto das instituições, além dos políticos locais manterem suas influências especificas e suas responsabilidades nas decisões políticas locais.

A questão da eficiência relativa do Estado estaria relacionada a sua desprivatização e sua capacidade fiscal. $\mathrm{O}$ autor chama atenção para o fato do caráter público das instituições estatais, pois algumas destas teriam sido apropriadas ou monopolizadas por grupos privados ou corporativos. Quanto à questão da capacidade fiscal ou o poder de fiscalização dos lucros do capital, para o autor, um Estado débil não costuma ser eficiente, em contraposição um Estado com poderosa capacidade fiscal costuma ser mais eficiente.

As políticas de identidade de grupos étnicos, de gênero, de sexualidade, etc. que teriam sido pouco observadas nos anos 60 e 70, hoje fariam parte constitutiva e central dos debates e das lutas políticas. Assim como a ênfase na importância da sociedade civil,

\begin{tabular}{llllll}
\hline Serviço Social \& Saúde & Campinas & v. 4 & n. 4 & p. 1-156 & Maio 2005 \\
\hline
\end{tabular}


segundo o autor nos anos 80 e 90 produziu-se um importante debate sobre o papel da sociedade civil, a cidadania e as relações destas com o Estado. Ainda segundo o autor, devemos analisar a sociedade civil juntamente com o Estado, pois entre as esferas existiria uma dialética que devemos analisar e compreender: na sociedade civil reclama-se e defende-se direitos, mas na esfera do Estado os direitos são reconhecidos, efetivados ou anulados.

\section{A SOCIEDADE CIVIL NO BRASIL}

Conforme o Grupo de Estudos sobre a Construção Democrática (1999) “o problema da construção da esfera pública tem sido tema recorrente na reflexão sobre a democracia no Brasil”. (GECD, p. 43) A questão estaria sendo tratada em duas dimensões que se cruzam: a primeira buscaria compreender a importância da construção da esfera pública na democratização da sociedade e, a segunda, buscaria analisar a contribuição dos espaços públicos para a democratização do Estado.

Segundo Evelina Dagnino (2002) a sociedade civil brasileira - com o fim do regime militar instalado em 1964 - experimenta a partir da década de 70 um ressurgimento que tem como eixo a oposição ao Estado autoritário. Segundo a autora com a volta das instituições democráticas formais básicas os diferentes projetos políticos dentro da própria sociedade civil teriam se explicitado e ajudado no entendimento da heterogeneidade da mesma. Do outro lado, a reconstituição das instituições democráticas formais básicas não produziu os encaminhamentos adequados por parte do Estado com relação aos problemas de exclusão e desigualdades sociais nas suas diferentes expressões, o que teria ampliado e radicalizado a noção de democracia e a necessidade de controle do Estado por parte da sociedade civil. A autora procura demonstrar que o processo de construção democrática não é linear e homogêneo, mas crivado de aspectos complexos, contraditórios e oscilantes nos quais o Estado tanto quanto a sociedade civil reproduzem concepções e interesses plurais e, por vezes, antagônicos. Em decorrência destas aferições a autora aponta como foco da natureza dos conflitos a dificuldade em partilhar efetivamente o poder de decisão. Nas suas palavras: "o que os espaços púbicos estão colocando é o aprendizado da tarefa da 
construção hegemônica, que requer o reconhecimento da pluralidade como ponto de partida de um processo de busca de princípios e interesses comuns em torno dos quais a articulação das diferenças abra caminho para a configuração do interesse público" (DAGNINO; 2002: 286).

\section{O ORÇAMENTO PARTICIPATIVO}

A implantação do Orçamento Participativo - OP em Porto Alegre, segundo Tarso Genro (1997), não teria servido apenas para incentivar a participação popular nos moldes da democracia formal, mas sim criar um novo centro decisório juntamente com o Poder Executivo e o Legislativo, democratizando a ação e as decisões políticas ao envolver cidadãos e buscar nestes espaços construir formas efetivas de "participação igual” ou "mais igual”. Um novo espaço público em que a população estabelece de maneira autônoma (por meio de um processo de democracia direta) suas prioridades e elege seus representantes para os fóruns deliberativos, criando o que o autor chamou de "esfera pública não-estatal”, onde a sociedade instituiria tanto o processo de co-gestão da cidade, quanto de controle social do Estado.

Leonardo Avritzer (2003) registra uma expansão da experiência do OP para uma centena de cidades brasileiras, e, em menor quantidade, para localidades européias e latinoamericanas. Ao lado disso, o autor adverte que embora muitas delas reivindiquem similaridade com a experiência porto-alegrense esta é decorrência de mais de uma década de experiência, demandou várias adaptações que resultaram em uma complexa "engenharia de participação”. Sendo assim, mesmo realçando sua importância para fortalecer a democracia local, frisa que promover a sua expansão ou repeti-la em outros ambientes não é tarefa simples de realizar.

Para efeito de estudos, o autor propõe a definição do OP como uma forma de "rebalancear a articulação entre a democracia representativa e a democracia participativa" (AVRITZER, p: 14), com base em quatro elementos: 1) cessão de soberania por quem detém o poder representativo local; 2) reintrodução de elementos de participação local (assembléias regionais, conselhos, etc.), combinando-se ai métodos de democracia participativa; 3) auto regulação soberana, a parir da definição de regras e procedimentos

\begin{tabular}{llllll}
\hline Serviço Social \& Saúde & Campinas & v. 4 & n. 4 & p. 1-156 & Maio 2005 \\
\hline
\end{tabular}


pelos participantes do OP e 4) reversão das prioridades de recursos públicos locais em prol das populações mais carentes.

O autor apresenta também quatro categorias que se mostram necessárias ao desenvolvimento e à existência do OP: 1) vontade política do partido que detém o poder; 2) a densidade associativa que corresponde ao grau de coesão e de organização da sociedade e da comunidade; 3) os elementos do desenho institucional; e 4) a capacidade administrativa e financeira para implantar a proposta.

Como pudemos perceber o Brasil vive um processo de redemocratização em paralelo a outro processo de reorganização do sistema capitalista avesso à democratização e à atuação coletiva.

\section{3) O OP CAMPINAS}

Campinas é a casa de um milhão de habitantes, com sérios problemas sócioespaciais, tem uma forte tradição de organização social e popular, que gerou diversos instrumentos de participação e de influência nas decisões do Estado. Como exemplo institucional podemos citar os 28 Conselhos Municipais em funcionamento regular. Valorizando a tradição organizativa independente do Estado, antes do iniciarmos as Assembléias Populares do OP, realizamos encontro que denominamos "Temos futuro porque temos passado". Entre os objetivos do encontro: homenagear os "anônimos" que protagonizaram um dos principais movimentos sociais que a cidade conheceu: a Assembléia do Povo de Campinas, um forte movimento popular que se iniciou na segunda metade dos anos 70, que articulou a periferia da cidade em trono de reivindicações ligadas ao combate à inflação e por infra-estrutura nas vilas construídas pela Cohab. Este evento também serviu para iniciarmos o debate da formulação da política de participação popular para a cidade de Campinas.

Orientada pelo Programa de Governo, a metodologia do OP estabeleceu um “processo de democracia direta”, seja no debate das definições das prioridades, seja na eleição e constituição das suas instâncias de representação.

Outros três princípios orientaram os trabalhos: o primeiro, estabelecer uma relação democrática de fato, mesmo que não de Direito, entre o Governo e as instâncias do

\begin{tabular}{llllll}
\hline Serviço Social \& Saúde & Campinas & v. 4 & n. 4 & p. 1-156 & Maio 2005 \\
\hline
\end{tabular}


OP. Ou seja, ainda que as definições das instâncias do OP não tenham força de lei, que provenham de um acordo tácito embora explícito entre Governo e cidadãos/ãs, essas decisões devem ser cumpridas. O segundo é a prática de uma avaliação democrática constante, como elemento retro-alimentador do processo. E o terceiro é a garantia do acesso dos cidadãos/ãs ao maior e melhor repertório possível de informações necessárias à tomada de decisões e realização das demais ações de controle sobre o Poder Público.

Tendo as orientações gerais e os princípios que deveriam nortear os trabalhos, iniciou-se uma fase de reuniões com lideranças sociais da cidade. Esta fase do trabalho teve três objetivos: a) reafirmar o compromisso de campanha; b) municiar as lideranças com informações sobre nossa proposta, ouvir suas dúvidas e, a partir delas, enriquecer o projeto e o entendimento de como encaminhá-lo e; c) aquecer a população, nossa equipe e o Governo, visando à implantação do Programa do OP.

\section{AS ASSEMBLÉIAS POPULARES REGIONAIS}

A cidade é dividida em 18 regiões administrativas, as quais foram consideradas como regiões do OP, onde a população definiu suas principais necessidades.

A utilização da divisão geográfica administrativa possibilitou envolver os Administradores/as Regionais e Subprefeitos/as nas diversas fases do OP e estes desempenharam papel fundamental, ainda possibilitou a aproximação das AR's e Subprefeituras da população, o que criou novas relações, mais democráticas e transparentes, quebrando a tradição de apadrinhamento até então dominante. 


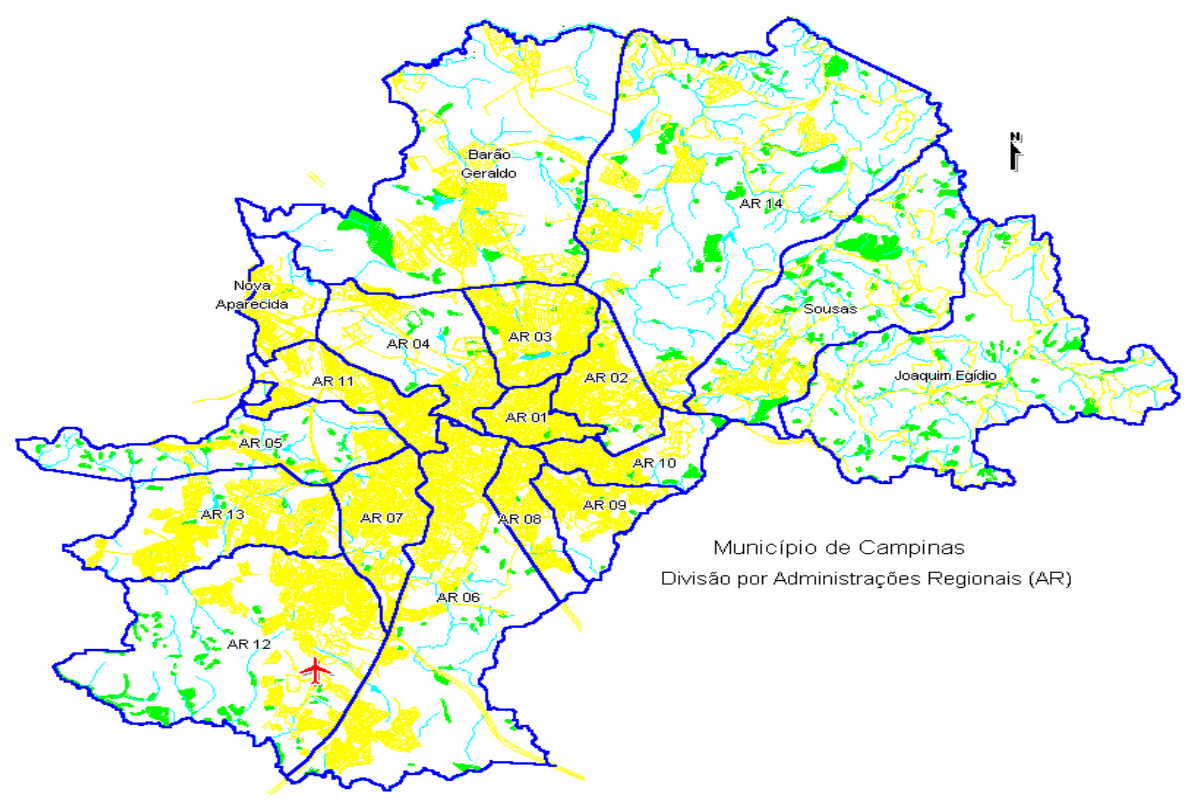

\section{AS ASSEMBLÉIAS POPULARES TEMÁTICAS}

Além das prioridades regionais, a participação ocorre também a partir de temas setoriais e transversais em oito Assembléias Populares Temáticas: Assistência Social, Saúde, Gestão, Educação, Cultura Esporte e Lazer, Desenvolvimento Econômico, Habitação e o que denominamos de Temas da Cidadania (trabalhando questões referentes aos seguintes segmentos: comunidade negra, homossexuais, idosos, juventude, mulheres, e portadores de necessidades especiais).

\section{1) AS FASES DO OP CAMPINAS}

O OP foi articulado enquanto um processo, ou seja, uma série de eventos que estão articulados entre si e que vão organizadamente acumulando informações e definições até se estabelecer plano de investimentos. O processo foi dividido em quatro grandes momentos:

a) A primeira rodada de Assembléias Populares;

b) As Assembléias Intermediárias;

c) A segunda rodada de Assembléias Populares, e

\begin{tabular}{lllll}
\hline Serviço Social \& Saúde & Campinas & v. 4 & n. 4 & p. 1-156
\end{tabular}
Maio 2005 
d) Os trabalhos do Conselho Municipal do Orçamento Participativo - COP.

\section{PRIMEIRA RODADA DE ASSEMBLÉIAS POPULARES}

A Primeira Rodada de Assembléias Populares tem dois objetivos: a) realizar uma prestação de contas à população presente com relação ao desempenho da Administração na região ou no tema, e b) eleger os Representantes Regionais ou Temáticos que comporão os respectivos Fóruns.

A cada dez pessoas presentes nas Assembléias elege-se um representante para compor os Fóruns de Representantes. Estes Representantes são eleitos conforme a participação dos bairros. Ou seja: o bairro que tiver mais participação na Assembléia elegerá mais Representantes.

Nas Assembléias Populares Temáticas, os Representantes são eleitos na proporção de um para cada dez pessoas presentes e credenciadas nas Assembléias, conforme a categoria de credenciamento (usuários, trabalhadores, prestadores de serviço, etc.). Portanto, para cada Região e Tema são formados Fóruns de Representantes. Os Representantes realizam trabalho voluntário, ou seja, não remunerado.

\section{A RODADA INTERMEDIÁRIA}

A rodada intermediária - organizada pelos Fóruns de Representantes - é o momento mais importante do OP, pois é nesta fase que a população autonomamente se reúne a partir de suas características e necessidades para debater, decidir e hierarquizar suas principais necessidades. Nesta fase compete ao Governo acompanhar os Fóruns, dando informações e suporte técnico necessários para a realização dos seus trabalhos.

\section{A SEGUNDA RODADA DE ASSEMBLÉIAS POPULARES}

A Segunda Rodada de Assembléias Populares tem três objetivos: 1) Apresentar a Previsão Orçamentária para o ano seguinte (previsão da Receitas e Despesas); 2) Recolher as prioridades definidas pelas Regiões e pelos Temas, e 3) Eleger os/as Conselheiros/as para o COP. 


\section{O CONSELHO DO OP}

O COP atualmente tem 102 Conselheiros, sendo 51 titulares e 51 suplentes, eleitos através do voto direto nas 18 regiões da cidade e nas plenárias temáticas. Cada região elege 04 Conselheiros, dois titulares e dois suplentes. As Assembléias Temáticas elegem um conselheiro titular e um suplente, para representar os temas da Assistência Social, Cultura Esporte e Lazer, Educação, Gestão, Habitação e Saúde. A temática de Desenvolvimento Econômico elege seis Conselheiros, três titulares e três suplentes, dois representando os produtores rurais, dois representando as micros e pequenas empresas, e a indústria e o comércio, os outros dois representam os setores da economia informal, as cooperativas e o movimento sindical. A Temática da Cidadania elege 12 Conselheiros sendo um titular e um suplente representando a comunidade negra, os homossexuais, os idosos, a juventude, as mulheres e os portadores de necessidades especiais. Os Conselheiros têm mandato de um ano - ou até a posse do Conselho do ano seguinte - e realizam trabalho voluntário, não remunerado.

O Governo participa do COP com direito a voz, mas sem direito a voto.

A eleição do COP é direta, todos os/as cidadãos/ãs com mais de 16 anos presentes e credenciados nas Assembléias têm direito ao voto. A eleição é realizada através de chapas e segue o critério da proporcionalidade direta, ou seja, a composição - quatro nas regiões e dois nos temas - terá a representatividade resultante da eleição, ou a chapa que obtiver mais votos terá mais representantes entre os conselheiros eleitos.

\section{4) ASPETOS DA DINÂMICA DO OP CAMPINAS}

Nesta parte apresentaremos e discutiremos alguns aspectos da experiência, dialogando com a observação de Göran Theborn (2004) que sugere analisar a sociedade civil juntamente com o Estado, pois entre as esferas existiria uma dialética que devemos analisar e compreender, sendo a sociedade civil, o local onde reclama-se e defende-se direitos, e a esfera do Estado, o local onde os direitos são reconhecidos, efetivados ou anulados.

\begin{tabular}{llllll}
\hline Serviço Social \& Saúde & Campinas & v. 4 & n. 4 & p. 1-156 & Maio 2005
\end{tabular} 


\section{1) A RELAÇÃO COM A SOCIEDADE CIVIL}

Iniciamos a implantação do programa do OP enfrentando os desafios de desmontar armadilhas administrativas, reconstruir o aparelho de Estado e inverter as prioridades de investimentos do poder púbico. Nesta conjuntura os movimentos sociais tiveram papel fundamental, pois se a densidade associativa ou o grau de organização da sociedade e da comunidade é condição, como aponta Avritzer (2003), Campinas tem uma forte tradição e esta organização influenciou na construção do “arranjo institucional” e determinou a dinâmica de participação da sociedade civil.

Os trabalhos junto à sociedade civil se iniciaram com reuniões junto às lideranças dos movimentos sociais e populares para discutir a dinâmica do OP. Esta fase propiciou um ambiente favorável na medida em que era o Governo, na pessoa da vice-prefeita que estava ali reafirmando o compromisso de campanha, discutindo e construindo com as lideranças a metodologia que orientou os trabalhos. Este movimento, além de criar um ambiente de reafirmação e construção coletiva, permitiu que as lideranças populares pudessem articular os movimentos e as organizações para participarem do processo de forma autônoma.

A atual composição do COP, com 102 conselheiros, é fruto do desenvolvimento do debate travado com a sociedade civil. Neste sentido, a primeira adaptação à metodologia aconteceu logo no primeiro ano, antes ainda da primeira rodada de Assembléias Populares, quando os movimentos dos homossexuais e do HIP HOP pleitearam representação direta no COP. Nas discussões, prevaleceu o entendimento que os homossexuais se caracterizam como um segmento social, portanto foram incorporados na temática da cidadania. O "HIP HOP” foi caracterizado como um movimento cultural, por isto, não foi incorporado com representação direta no COP, coube ao mesmo buscar discutir suas demandas nos espaços até então existentes, contudo foi o primeiro movimento o sentido de criar a Temática de Cultura, que envolveu outros movimentos culturais.

A Temática de Gestão foi pensada para se debater com o conjunto da sociedade quais os investimentos prioritários na reconstrução democrática do aparelho de Estado.

A Assembléia Temática de Desenvolvimento Econômico e Tributação foi proposta após críticas feitas por alguns segmentos sociais da cidade. A Temática teve como

\begin{tabular}{llllll}
\hline Serviço Social \& Saúde & Campinas & v. 4 & n. 4 & p. 1-156 & Maio 2005
\end{tabular}


objetivo incorporar com representação direta alguns segmentos relacionados à economia formal e informal e ao mundo do trabalho. Na primeira avaliação da Temática os produtores rurais conquistaram representação direta no Conselho.

A definição de incorporar segmentos sociais tradicionalmente discriminados e mantidos à margem do processo político nos trouxe elementos para pensarmos a democratização da sociedade civil. Como exemplo podemos citar os homossexuais. No primeiro ano a prioridade da AR1 - região central da cidade - foi segurança, procurava-se proibir a atuação dos profissionais do sexo na referida região. O argumento utilizado foi a insegurança gerada pela movimentação das pessoas no local. Os homossexuais também reivindicaram segurança, desdobrada em cursos de capacitação para a Guarda Municipal e a criação do Disque Denuncia. O Conselho, após um intenso debate sobre o significado da "segurança”, aprovou as demandas dos homossexuais, o que, por outro lado, geram um conjunto ainda maior de discussão entre o Governo, os interessados diretos e outros cidadãos envolvidos. Seja porque a burocracia e o Governo nunca tinham enfrentado nenhum debate aberto parecido e quando foi obrigado a fazer não o fez sem ter que superar determinadas questões conceituais, ou ainda porque foram enormes as dificuldades legais impostas para o poder público poder alugar imóvel para o Disque Denuncia.

\section{AS DINÂMICAS DAS INSTÂNCIAS}

No “arranjo institucional” ou na metodologia, são três as instâncias de deliberação: as Assembléias Populares, os Fóruns de Representantes e o COP.

As Assembléias Populares Regionais e Temáticas elegem as instâncias de representação do OP (os Representantes e os Conselheiros). Participam das assembléias todos os cidadãos/ãs interessados/as na pauta.

Os Representantes são eleitos na proporção da participação dos bairros, dos setores ou dos seguimentos presentes e credenciados nas Assembléias Populares. Aos Representantes é delegada a responsabilidade de articular as Assembléias Intermediárias onde se inicia as definições das prioridades das regiões, dos seguimentos e dos temas a partir de uma auto-definição de características ou interesses comuns - os moradores do mesmo bairro, os militantes dos mesmo movimento social, ou de frações do movimento. 
Portanto, primeiro os mais iguais se reúnem e definem autonomamente suas prioridades para depois, nos respectivos Fóruns de Representantes, confrontá-las com as outras prioridades da região, do seguimento ou do tema. A premissa é primeiro possibilitar articulação entre os mais iguais.

É importante perceber que a rodada de Assembléias Intermediárias é o primeiro momento de definição de prioridades. Ou seja, os Representantes e os Conselheiros trabalham com as demandas aprovadas pelas Assembléias Intermediárias. O escopo de prioridades em discussão é definido, portanto, pelo conjunto das Assembléias Intermediárias e pelas pessoas que delas participaram.

O trabalho do COP inicia-se com a definição do seu regimento interno. Neste os Conselheiros Suplentes têm direito de participar de todos os eventos e das atividades de trabalho com direito a voz, e com direito a voto quando da ausência do titular. Como parte dos trabalhos são organizadas reuniões com representantes das áreas da administração, curso sobre orçamento público e a visitas pelas regiões da cidade - durante a visita cada Conselheiro apresenta sua região e defende suas demandas.

O Conselho tem sido subdividido em Grupos de Trabalhos - GT’s à partir das demandas a serem avaliadas e de acordo com os interesses dos conselheiros, ou seja, cada Conselheiro opta livremente por participar de um ou mais grupos na medida dos seus interesse. Os GT’s se reúnem com as respectivas áreas da Administração responsáveis pelas demandas para, em conjunto, formularem proposta a ser apresentada ao Conselho.

\section{A INTENSIDADE E A DINÂMICA DA PARTICIPAÇÃO}

Como já foi dito, Campinas tem uma forte tradição de organização popular e já na apresentação da proposta para as lideranças, 1.081 pessoas participaram do debate.

A metodologia acordada determinou que os trabalhos se dividiriam em quatro grandes momentos ou fases de um ciclo. O primeiro, a primeira rodada de Assembléias Populares Regionais ou Temáticas, envolveu nos três primeiros anos 22.822 pessoas, e elegeu 2.445 Representantes.

A segunda fase, as Assembléias Intermediárias, organizada pelos respectivos Fóruns de Representantes, e contou com a participação de 30.653 pessoas.

\begin{tabular}{llllll}
\hline Serviço Social \& Saúde & Campinas & v. 4 & n. 4 & p. 1-156 & Maio 2005
\end{tabular}


O terceiro momento, a segunda rodada de Assembléias Populares Regionais ou Temáticas, onde os representes apresentavam as prioridades da região ou do tema, ou, o resultado dos seus trabalhos, e são eleitos os/as Conselheiros/as da região ou do tema, contou com a participação de 19.055 .

O quarto momento é da definição do plano de investimentos contido no projeto de Lei Orçamentária entregue á Câmara de Vereadores para sua apreciação.

É interessante perceber que a participação das pessoas na segunda rodada de assembléias é menor que a participação na primeira rodada e nas Assembléias Intermédias. Alguns elementos ajudam a entender este fenômeno. Em primeiro lugar o OP é articulado pelas lideranças das regiões, dos segmentos ou dos temas. Estas lideranças sabem diferenciar nas fases do OP quais as mais importantes.

Uma evidência é a menor participação no segundo ano na primeira rodada de Assembléias Populares. Este fato ocorre quando da percepção por parte das lideranças que era importante eleger representantes em quantidade, contudo pelas regras de definição de prioridades adotadas não bastava apenas ter um numero significativo de representantes.

A metodologia que organiza o processo de definição de prioridades é uma composição de variáveis políticas e matemáticas, portanto não é apenas uma questão de maioria ou minoria.

Cabe aos Fóruns de Representantes Regionais recolher as prioridades aprovadas nas Assembléias Intermediárias, classificá-las dentro dos temas de políticas públicas, para em seguida, perceber, a partir das demandas, quais os temas mais demandados. Esta hierarquização é conseqüência das diferentes demandas aprovadas pelo diferentes bairros, portanto se mais bairros aprovaram demandas relacionadas à educação, por exemplo, o tema educação é o tema prioritário. Cada região indica para o COP um conjunto de demandas contidas em um conjunto de temas priorizados nas Assembléias Intermediárias, os Representantes não podem mudar a ordem dos temas, cabe a estes definir quais as demandas em cada um dos temas até o total de demandas a serem encaminhadas. 


\section{Quadro 01}

Participação da População nas Assembléias do Orçamento Participativo de Campinas

\begin{tabular}{|c|c|c|c|c|c|c|c|c|c|c|c|c|c|c|}
\hline & $\begin{array}{c}1^{\mathrm{a}} \\
\text { rodada }\end{array}$ & & & $\begin{array}{c}\text { Represen- } \\
\text { tantes }\end{array}$ & & & \begin{tabular}{|c|} 
Interme- \\
diárias
\end{tabular} & & & $\begin{array}{c}2^{\mathrm{a}} \\
\text { rodada }\end{array}$ & & & TOTAL & $\%$ \\
\hline LOCAL / TEMA & 2001 & 2002 & 2003 & 2001 & 2002 & 2003 & 2001 & 2002 & 2003 & 2001 & 2002 & 2003 & & \\
\hline REGIONAL 01 & 93 & 57 & 116 & 9 & 6 & 7 & $\mathrm{n} / \mathrm{d}$ & 31 & 162 & 21 & 27 & 41 & 548 & 0,76 \\
\hline REGIONAL 02 & 528 & 466 & 512 & 53 & 46 & 54 & $\mathrm{n} / \mathrm{d}$ & 547 & 655 & 505 & 304 & 368 & 3.885 & 5,36 \\
\hline REGIONAL 03 & 751 & 220 & 119 & 64 & 26 & 16 & $\mathrm{n} / \mathrm{d}$ & 390 & 387 & 471 & 211 & 166 & 2.715 & 3,74 \\
\hline REGIONAL 04 & 180 & 269 & 72 & 18 & 30 & 6 & $\mathrm{n} / \mathrm{d}$ & 391 & 163 & 170 & 68 & 49 & 1.362 & 1,88 \\
\hline REGIONAL 05 & 162 & 96 & 112 & 20 & 10 & 10 & $\mathrm{n} / \mathrm{d}$ & 225 & 299 & 85 & 58 & 92 & 1.129 & 1,56 \\
\hline REGIONAL 06 & 1.025 & 540 & 341 & 103 & 54 & 39 & $\mathrm{n} / \mathrm{d}$ & 1.902 & 1.477 & 1.243 & 1643 & 449 & 8.620 & 11,88 \\
\hline REGIONAL 07 & 718 & 288 & 284 & 77 & 38 & 29 & $\mathrm{n} / \mathrm{d}$ & 738 & 674 & 433 & 226 & 369 & 3.730 & 5,14 \\
\hline REGIONAL 08 & 117 & 109 & 103 & 12 & 12 & 15 & $\mathrm{n} / \mathrm{d}$ & 263 & 182 & 178 & 87 & 52 & 1.091 & 1,50 \\
\hline REGIONAL 09 & 321 & 253 & 118 & 32 & 30 & 15 & $\mathrm{n} / \mathrm{d}$ & 465 & 337 & 230 & 156 & 85 & 1.965 & 2,71 \\
\hline REGIONAL 10 & 128 & 260 & 259 & 13 & 26 & 26 & $\mathrm{n} / \mathrm{d}$ & 290 & 415 & 230 & 159 & 239 & 1.980 & 2,73 \\
\hline REGIONAL 11 & 334 & 145 & 182 & 41 & 18 & 22 & $\mathrm{n} / \mathrm{d}$ & 446 & 500 & 346 & 345 & 294 & 2.592 & 3,57 \\
\hline REGIONAL 12 & 622 & 894 & 635 & 63 & 94 & 70 & $\mathrm{n} / \mathrm{d}$ & 2.214 & 1.894 & 574 & 571 & 544 & 7.948 & 10,96 \\
\hline REGIONAL 13 & 757 & 486 & 292 & 77 & 55 & 33 & $\mathrm{n} / \mathrm{d}$ & 1.620 & 1.689 & 340 & 249 & 255 & 5.688 & 7,84 \\
\hline REGIONAL 14 & 366 & 94 & 66 & 37 & 12 & 6 & $\mathrm{n} / \mathrm{d}$ & 175 & 174 & 287 & 114 & 52 & 1.328 & 1,83 \\
\hline
\end{tabular}




\section{Quadro 01}

Participação da População nas Assembléias do Orçamento Participativo de Campinas (Continuação)

\begin{tabular}{|c|c|c|c|c|c|c|c|c|c|c|c|c|c|c|}
\hline & $\begin{array}{c}1 \mathrm{a} \\
\text { rodada }\end{array}$ & & & $\begin{array}{c}\text { Represen- } \\
\text { tantes }\end{array}$ & & & $\begin{array}{l}\text { Interme- } \\
\text { diárias }\end{array}$ & & & \begin{tabular}{|c|}
$2 a$. \\
rodada
\end{tabular} & & & Total & $\%$ \\
\hline LOCAL / TEMA & 2001 & 2002 & 2003 & 2001 & 2002 & 2003 & 2001 & 2002 & 2003 & 2001 & 2002 & 2003 & & \\
\hline BARÃO GERALDO & 205 & 454 & 224 & 22 & 49 & 27 & $\mathrm{n} / \mathrm{d}$ & 730 & 494 & 125 & 152 & 152 & 2.536 & 3,50 \\
\hline SOUSAS & 230 & 253 & 135 & 23 & 27 & 16 & $\mathrm{n} / \mathrm{d}$ & 123 & 211 & 110 & 123 & 129 & 1.314 & 1,81 \\
\hline JOAQUIM EGÍDIO & 66 & 51 & 35 & 7 & 10 & 9 & $\mathrm{n} / \mathrm{d}$ & 119 & 107 & 76 & 54 & 30 & 538 & 0,74 \\
\hline NOVA APARECIDA & 577 & 364 & 159 & 58 & 43 & 15 & $\mathrm{n} / \mathrm{d}$ & 670 & 357 & 277 & 309 & 42 & 2.755 & 3,80 \\
\hline SAÚDE & 93 & 164 & 328 & 9 & 16 & 35 & $\mathrm{n} / \mathrm{d}$ & 279 & 196 & 103 & 102 & 90 & 1.355 & 1,87 \\
\hline ASSISTÊNCIA & 274 & 221 & 405 & 27 & 26 & 42 & $\mathrm{n} / \mathrm{d}$ & 1.016 & 631 & 92 & 135 & 153 & 2.927 & 4,04 \\
\hline CIDADANIA & 492 & 282 & 330 & 49 & 53 & 45 & $\mathrm{n} / \mathrm{d}$ & 1.784 & 1.921 & 286 & 260 & 400 & 5.755 & 7,93 \\
\hline CULTURA, ESPORTE E LAZER & \multirow{4}{*}{191} & \multirow{4}{*}{$\begin{array}{l}604 \\
436 \\
156\end{array}$} & \multirow{4}{*}{$\begin{array}{l}586 \\
901 \\
279 \\
119\end{array}$} & & 61 & 59 & $\mathrm{n} / \mathrm{d}$ & 61 & 282 & \multirow{4}{*}{291} & \multirow{4}{*}{$\begin{array}{c}387 \\
564 \\
50\end{array}$} & \multirow{4}{*}{$\begin{array}{c}381 \\
361 \\
67 \\
68\end{array}$} & 2.301 & 3,17 \\
\hline DESENVIOLVIMENTO ECONÔMICO & & & & & 42 & 91 & $\mathrm{n} / \mathrm{d}$ & 596 & 248 & & & & 3.106 & 4,28 \\
\hline EDUCAÇÃO & & & & 19 & 17 & 28 & $\mathrm{n} / \mathrm{d}$ & 54 & 107 & & & & 1.195 & 1,65 \\
\hline GESTÃO & & & & 7 & $\mathrm{n} / \mathrm{d}$ & 11 & $\mathrm{n} / \mathrm{d}$ & & 161 & & & & 348 & 0,48 \\
\hline HABITAÇÃO & \multirow[b]{2}{*}{8.230} & \multirow{2}{*}{$\begin{array}{c}244 \\
7.406\end{array}$} & \multirow{2}{*}{$\begin{array}{c}474 \\
7.186\end{array}$} & & 26 & 52 & $\mathrm{n} / \mathrm{d}$ & 1.016 & 785 & \multirow[b]{2}{*}{6.473} & \multirow{2}{*}{$\begin{array}{c}648 \\
7.002\end{array}$} & \multirow{2}{*}{$\begin{array}{c}652 \\
5.580\end{array}$} & 3.819 & 5,27 \\
\hline TOTAL & & & & 840 & 827 & 778 & $\mathbf{0}$ & 16.145 & 14.508 & & & & 72.530 & 100,00 \\
\hline
\end{tabular}

Fonte: Coordenadoria Especial da Participação Popular e do Orçamento Participativo - PMC

\begin{tabular}{llllll}
\hline Serviço Social \& Saúde & Campinas & v. 4 & n. 4 & p. 1-156 & Maio 2005
\end{tabular} 
A aprovação das demandas depende da articulação das lideranças a partir da metodologia do OP, portanto depende da apropriação por parte das lideranças da importância de cada uma das fases no processo. Esta situação ajuda a entender a queda da participação na primeira rodada de assembléias que elegem os representes, assim como a importância da auto-regulação do OP. Ou seja, as lideranças devem definir autonomamente quais as regras que orientaram os debates.

Vale a pena destacar também que a participação mais intensa aconteceu nas regiões mais carentes. Fundamentalmente porque estas regiões mantêm um nível de organização política importante para buscar superar o Estado de abandono à qual foram relegadas. Esta organização política num ambiente de democracia participativa permite fazer destas regiões, até então política e infraestruturalmente abandonadas, espaços vivos de disputa política para serem re-inseridas nas prioridades de investimentos da cidade e superar a dívida social existente.

Não por acaso também a Temática da Cidadania teve expressiva participação, fundamentalmente porque os seguimentos viram no OP a possibilidade de terem suas necessidades legitimadas no âmbito da sociedade civil e serem efetivas pelo Estado.

\section{2) A RELAÇÃO COM O ESTADO}

A Lei Orçamentária Anual (LOA), ou o chamado orçamento, expressa um planejamento sobre o que e como se pretende arrecadar e como gastar o dinheiro público. Portanto expressa uma priorização das fontes de receitas e das ações a serem desenvolvidas, ou ainda, a vontade política do governo em atender determinados interesses que com ele se relaciona.

O modelo neoliberal tem na Lei de Responsabilidade Fiscal (LRF) o suporte necessário para colocar o pagamento das dívidas como prioridade de ação do Estado, ou seja, primeiro paga-se as dívidas para depois investir e atender necessidades sociais básicas. Neste aspecto o OP estabelece uma contradição com a lógica da LRF e com o modelo neoliberal na medida que, com o OP o governo tem que aumentar seus recursos e sua capacidade de investimentos para atender as demandas da população, estabelecendo prioridades diferentes da lógica neoliberal.

\begin{tabular}{llllll}
\hline Serviço Social \& Saúde & Campinas & v. 4 & n. 4 & p. 1-156 & Maio 2005
\end{tabular} 
As discussões da totalidade da capacidade de investimentos geraram implicações na dinâmica orçamentária e na relação da burocracia com a sociedade civil. Assim como as execuções das demandas do OP explicitam um outro grande conjunto de dificuldades, e limites relacionados com o modelo burocrático do aparelho de Estado.

\section{A DINÂMICA ORÇAMENTÁRIA}

O debate dos $100 \%$ da capacidade de investimento nos permite perceber algumas alterações da lógica de funcionamento político financeiro do Estado. No primeiro ano de Governo encontramos um orçamento que em nada dialogava com nossas expectativas, agravado pelo fato do não conhecimento da estrutura existente e do seu custo de funcionamento. O primeiro movimento feito foi congelar o Custeio - ou o custo de funcionamento da estrutura do aparelho de Estado -, e aumentar a arrecadação para gerar capacidade de investimento e de gestão dos recursos disponíveis, pois o aparelho de Estado vinha reproduzindo rotinas cuja racionalidade e articulação, estavam estruturadas numa perspectiva privatista de pequenos grupos, o que as tornava inadequadas à implementação do projeto democrático e popular.

A manutenção desta estratégia somada às baixas taxas de crescimento econômico trouxe-nos dificuldades, contudo aponta um caminho para ampliar e potencializar as discussões da totalidade do orçamento, pois na medida que o custeio se congela, qualquer crescimento deste - para além dos reflexos das decisões passadas de investimento - só poderia ser efetuado se debatido também no OP. A projeção destes movimentos nos permite visualizar a construção de um orçamento inteiramente conseqüente com um processo de democracia direta.

\section{A RELAÇÃO COM A BUROCRACIA}

Partimos do entendimento que nos limites da democracia representativa os governos se adequam às estruturas burocráticas do aparelho de Estado para se relacionarem com a sociedade civil e efetivarem suas necessidades. Neste sentido a relação do Estado com a sociedade civil é feita a partir de setores como saúde, educação, assistência, por exemplo - levando em consideração que cada um destes setores tem sua lógica de 
funcionamento mais ou menos independente do conjunto do governo -, superar a lógica setorial é o primeiro desafio para se democratizar o Estado.

O tema da Assistência Social nos ajuda a perceber a dinâmica da relação do Estado com o OP. Desde o primeiro ano a construção da temática tem dependido do envolvimento dos profissionais da área. O trabalho se iniciou com os profissionais da área envolvendo os usuários nas discussões. A primeira conselheira desenvolveu sua tarefa estabelecendo uma aliança com os Conselheiros da região central (AR1) da cidade que também haviam apresentado demandas referentes ao tema. Esta atuação conjunta possibilitou um resultado positivo que surpreendeu todos os envolvidos.

A Constituição Federal obriga que o poder público invista 25\% das suas receitas correntes em educação. Este preceito constitucional não vinha sendo respeitado no governo anterior, e ao se buscar atendê-lo, o orçamento da área teve um acréscimo da ordem de R\$ 12 milhões, estes novos recursos, por serem novos não tinham nenhuma pré-destinação, os conselheiros ao apropriarem-se da informação levantaram - baseando-se nas orientações apresentadas pelo governo de se debater a totalidade da capacidade de investimentos - a necessidade destes recursos serem objeto de discussão e deliberação do COP. Esta situação acarretou um resultado onde as demandas de 2001 da educação foram basicamente atendidas dentro dos $25 \%$ do orçamento destinado ao tema. No total de investimentos, que até então vinha sendo debatido como R 38 milhões, com a incorporação dos recursos da educação ao plano de investimento de 2002, este atingiu a ordem de R 51 milhões.

Na Saúde, área onde se observa uma longa história de construção democrática, os trabalhos e os resultados são importantes para o entendimento e apropriação da dinâmica do OP. Assim como em outras temáticas, as demandas referentes ao tema originam-se nas regiões e nas suas assembléias temáticas. As demandas regionais têm caráter mais infraestruturais, ou seja, geralmente as regiões demandam a construção de Centros de Saúde ou a implantação/ ampliação de serviços para a região. As demandas dos segmentos sociais buscam atender interesses destes, como exemplo, podemos citar os medicamentos geriátricos, o combate à anemia falciforme, ou ainda a capacitação para atendimentos dos homossexuais. As demandas apresentadas a partir da Temática da Saúde dialogam mais com as discussões realizadas nas conferências ou com o acumulo da burocracia. Esta

\begin{tabular}{llllll}
\hline Serviço Social \& Saúde & Campinas & v. 4 & n. 4 & p. 1-156 & Maio 2005
\end{tabular} 
situação é conseqüência em primeiro lugar dos públicos participantes das diferentes assembléias. Nas discussões regionais e dos segmentos sociais as questões se concentram em interesses diretos dos participantes, demandas com menor capacidade de organização ou que há muito tempo são reclamadas. A composição da participação na Temática da Saúde corresponde a trabalhadores da área e militantes do tema que, na maioria, são também membros de Conselhos Locais de Saúde ou do Conselho Municipal, portanto representam um acúmulo de discussões nos moldes da sua importante tradição democrática.

Esta realidade não é própria da saúde, ainda que as intensidades sejam diferentes. Na dinâmica do OP temos as Assembléias Temáticas de Assistência Social, Educação, Cultura Esporte e Lazer, Desenvolvimento Econômico, Habitação, Saúde, Gestão, e o que denominamos de Temas da Cidadania. Na temática de Gestão participam os trabalhadores do serviço público municipal, portanto o debate esta intrinsecamente relacionado à questões do aparelho de Estado. Nas temáticas da Cidadania e Desenvolvimento Econômico, os participantes são, majoritariamente, membros da sociedade civil que se relacionam com os temas. Na habitação a participação dos profissionais também é importante, contudo esta se caracteriza mais como facilitadora do processo, ficando para os usuários a preponderância das deliberações.

Nas Assembléias Temáticas de Assistência Social, Educação, Cultura Esporte e Lazer e Saúde percebemos uma grande participação e o envolvimento dos profissionais das áreas. As categorias de credenciamento nestas assembléias são basicamente quatro: trabalhadores, usuários, prestadores de serviços e interessados o tema.

Dentre os resultados, a Assistência Social tendeu a uma queda nos valores orçamentários a ela destinados, mas manteve participação importante no processo, inclusive ampliando e diversificando o público das assembléias. A educação não chegou a ter forte participação nas suas assembléias temáticas, mas nas regiões as demandas sempre foram representativas. O debate ampliou-se para outros espaços, por exemplo, os Conselhos de Escola e o "Programa Conta Escola". No que se refere às demandas aprovadas buscou-se

2 O "Programa Conta Escola” é um programa desenvolvido na secretaria de educação que busca descentralizar - através dos Conselhos de Escolas - as decisões de pequenas compras e intervenções de manutenção.

\begin{tabular}{llllll}
\hline Serviço Social \& Saúde & Campinas & v. 4 & n. 4 & p. 1-156 & Maio 2005
\end{tabular} 
sempre contemplar apontamentos regionais e temáticos quando a questão era ampliação do número de vagas, contudo, na execução, as prioridades regionais que não estavam previstas no "planejamento" da Secretaria têm enfrentado maiores dificuldades operacionais.

$\mathrm{Na}$ saúde o problema se amplia. As discussões sempre foram tensas e os representantes do Governo, por terem tradição no modelo vigente de construção política, sempre trabalharam para aprovar mais demandas originárias da temática ou que dialogavam com os resultados das conferencias, do que das regiões. Quando alguma demanda aprovada não constava do plano de ação da área, estas também têm enfrentado diferentes situações de dificuldades na sua execução.

Além dos problemas particulares de cada setor, no primeiro ano de execução das demandas enfrentamos um conjunto de dificuldades e a baixa efetivação das demandas deveu-se mais a questões de caráter estrutural da burocrática do que falta de recursos orçamentários. Explicando: as demandas aprovadas no primeiro ano, na sua maioria, obras em locais com problemas fundiários e de custo de execução elevado. Uma baixa capacidade de avaliação técnica das demandas e de dinamização da burocracia inviabilizou agilizar as execuções, o que por outro lado exigiu maior capacitação do Governo e dos Conselheiros na avaliação das demandas e no acompanhamento da execução orçamentária.

\section{A DEMOCRATIZAÇÃO DOS INVESTIMENTOS}

Os trabalhos do Conselho dão continuidade aos trabalhos dos Fóruns de Representantes. Portanto todas as demandas avaliadas no Conselho estão legitimadas e muitas delas são aprovadas após serem defendidas apresentando como argumento as mobilizações realizadas e quantas pessoas serão beneficiadas se forem efetivadas.

Este quadro traz uma grande complexidade e um alto grau de responsabilização aos participantes do debate. O trabalho de priorização das demandas feito pelo COP é subsidiado por três critérios. São eles: primeiro, a ordem de prioridade da demanda definida na região ou no tema. O segundo é o índice de carência da região e, o terceiro critério, é a quantidade de população a ser beneficiada se aquela demanda for aprovada. Em 2003, para também subsidiar seu trabalho, o COP contou com as informações do Mapa da Vulnerabilidade Social de Campinas. O próprio mapa foi uma demanda aprovada em 2001.

\begin{tabular}{llllll}
\hline Serviço Social \& Saúde & Campinas & v. 4 & n. 4 & p. 1-156 & Maio 2005
\end{tabular} 
É importante registrar que um conjunto grande de demandas é executado a partir de um conjunto ainda maior de ações. Como exemplo podemos citar a prioridade 01 (um) da Temática de Habitação para o no ano de 2003, regularização fundiária. Com o atendimento desta demanda, dezenas de núcleos e/ ou ocupações estão sendo regularizados. Outro exemplo, na Temática da Assistência - ampliar os investimentos para ONG’s que desenvolvem atividades com crianças e adolescentes, ou ainda, a prioridade 02 (dois) da Educação - infra-estrutura (manutenção e reformas). Com essa informação queremos afirmar que a dinâmica de execução das demandas coloca no processo um grau ainda maior de complexidade e de resultados na dinâmica da relação do Estado com a sociedade civil.

O quadro 02 (abaixo) nos permite perceber um pouco do resultado deste trabalho, quais são as regiões e os temas que mais tiveram demandas aprovadas.

Podemos perceber que a área da Educação foi a mais contemplada em número de demandas, com 92 ou 21\%; seguida pela Habitação, com 68 ou 15\%; e Obras com 46 ou 10\% - a maior parte pavimentação - mas, também, iluminação e urbanização de córregos.

Não podemos deixar de chamar atenção para o fato de que $10 \%$ das demandas aprovadas pelo Conselho serem da Temática da Cidadania. Temática que envolve segmentos sociais importantes para a construção de uma Campinas mais democrática na sua forma de organização política, na aceitação das diferenças e no atendimento de necessidades específicas.

Os dados mostram também que as regiões que mais tiveram demandas atendidas foram as das Administrações Regionais 12 e 06. Respectivamente, Ouro Verde e/ ou dos DIC’s e a região que engloba o Parque Oziel até a região do Aeroporto Internacional de Viracopos, ou o corredor Santos Dumond. As regiões, juntas, conquistaram 53 demandas ou $12 \%$. 
Quadro 02 - Cruzamento das demandas aprovadas pelo COP por região, tema e valores anos de 2001, 2002 e 2003.

\begin{tabular}{|c|c|c|c|c|c|c|c|c|c|c|c|c|c|c|c|c|c|c|c|c|c|c|c|c|c|c|c|c|}
\hline \multirow{2}{*}{$\begin{array}{c}\text { TEMAS/ } \\
\text { REGIÕES/ } \\
\text { SEGMENTOS }\end{array}$} & \multicolumn{18}{|c|}{ REGIÕES } & \multicolumn{7}{|c|}{ SEGMENTOS* } & \multirow{2}{*}{ TOTAL } & \multirow{2}{*}{$\%$} & \multirow{2}{*}{ Total de $\mathbf{R} \$$} \\
\hline & $\mathbf{1}$ & 2 & 3 & 4 & 5 & 6 & 7 & 8 & 9 & 10 & 11 & 12 & 13 & 14 & JOQ & SOU & BG & AP & NEG & PNE & JUV & HOM & MUL & I DOS & CI DADE & & & \\
\hline Assistência & 6 & & 1 & & & 1 & 1 & & & 1 & & 1 & 2 & & & & & 2 & & 2 & & & 1 & 1 & 22 & 41 & 9,3 & $11.416 .835,76$ \\
\hline Cidadania & & & & & & & & & & & & & & & & & & & 3 & & 1 & 1 & 1 & & & 6 & 1,4 & $5.604 .200,00$ \\
\hline Cultura/ Esporte & 2 & 4 & 1 & & 1 & 1 & 2 & \begin{tabular}{l|l}
3 \\
\end{tabular} & 2 & 3 & & & & & 3 & & 1 & 1 & 3 & & 2 & 1 & 1 & 7 & 1 & 39 & 8,9 & $11.201 .587,16$ \\
\hline $\begin{array}{l}\text { Desenvolvimento } \\
\text { Econômico }\end{array}$ & 2 & & & & & & & & & & & & & & & & & & & 1 & 2 & 1 & 2 & & 8 & 16 & 3,6 & $4.146 .000,00$ \\
\hline Educação & & 3 & 3 & 2 & 3 & 8 & \begin{tabular}{l|l}
3 \\
\end{tabular} & 1 & 6 & 6 & 5 & 6 & 5 & 1 & & 1 & 2 & 3 & 1 & & 1 & 3 & & & 29 & 92 & 20,9 & $36.957 .120,00$ \\
\hline Gestão & & & & & & & & & & & & & & & & & & & & & & & & & 13 & 13 & 3,0 & $7.385 .600,00$ \\
\hline Habitação & & 11 & 13 & 4 & 4 & 3 & 2 & 2 & 4 & 3 & 2 & 3 & 2 & 1 & & 2 & 1 & 3 & & & & & & & 8 & 68 & 15,5 & $19.280 .996,00$ \\
\hline Meio Ambiente & 1 & & & & & & & & & & & & & & 1 & & & & & & & & & & & 2 & 0,5 & $2.666 .000,00$ \\
\hline Obras & & 2 & 2 & & 1 & 5 & 10 & 4 & 3 & 2 & 1 & 5 & 4 & 2 & & 1 & & 2 & & & & & & & 2 & 46 & 10,5 & $52.021 .669,11$ \\
\hline Saneamento & & & 2 & 2 & 3 & 4 & 2 & 1 & & 1 & 6 & 6 & 1 & 6 & & 4 & 7 & 2 & & & & & & & & 47 & 10,7 & $18.123 .000,00$ \\
\hline Saúde & & 1 & & & 2 & 3 & 1 & 2 & & 2 & 3 & 5 & 3 & & 1 & 2 & 1 & 1 & & 1 & & 1 & 1 & 2 & 9 & 41 & 9,3 & $27.145 .850,00$ \\
\hline Segurança & 2 & & & 1 & 1 & 1 & & & 1 & & & 1 & 1 & & 1 & 1 & 1 & & & & & 2 & & & & 13 & 3,0 & $4.476 .250,00$ \\
\hline $\begin{array}{l}\text { Serviços } \\
\text { Públicos }\end{array}$ & & & & & & & 1 & & & & 1 & & 1 & 1 & 1 & & & & & & & & & & 1 & 6 & 1,4 & $2.927 .000,00$ \\
\hline Transporte & 1 & & & & & & & & 3 & & & & & 1 & & & 3 & & & 2 & & & & & & 10 & 2,3 & $2.496 .000,00$ \\
\hline Total & 14 & 21 & 22 & 9 & 15 & $26:$ & 22 & 13. & 19 & 18 & 18 & 27 & 19 & 12 & 7 & 11 & 16 & 14 & 7 & 6 & 6 & 9 & 6 & 10 & 93 & 440 & 100,0 & 205.848.108,03 \\
\hline$\%$ & 3,2 & 4,8 & 5,0 & 2,03 & 3,4 & 5,95 & 5,03 & 3,04 & \begin{tabular}{l|l|l}
4,3 & 2 \\
\end{tabular} & 4,1 & 4,1 & 6,1 & 4,3 & 2,7 & 1,6 & 2,5 & 3,6 & 3,2 & 1,6 & 1,4 & 1,4 & 2,0 & 1,4 & 2,3 & 21,1 & 100,0 & & \\
\hline
\end{tabular}

Fonte: Coordenadoria Especial da Participação Popular e do Orçamento Participativo - PMC

* Abreviações utilizadas no quadro: NEG = Comunidade Negra; PNE Portadores de Necessidades Especiais; JUV = Juventude; HOM= Homossexuais; MUL= Mulheres; IDOS= Idosos.

\begin{tabular}{llllll}
\hline Serviço Social \& Saúde & Campinas & v. 4 & n. 4 & p. 1-156 & Maio 2005
\end{tabular}


Como podemos perceber no quadro 02, o tema obras foi o que mais teve recursos destinados pelo COP. As 46 demandas aprovadas, cerca de 10\%, comprometeram 29\% dos recursos do OP. Poderíamos apresentar o conjunto das demandas aprovadas e demonstrar a importância de cada uma delas, mas, só a título de exemplo, citamos a pavimentação do itinerário de ônibus da região do Campo Grande que vai Bairro Satélite Ires I até o Campina Grande, beneficiando mais de 70.000 pessoas.

Os dados demonstram que a participação popular na definição dos recursos públicos prioriza gastos nas áreas sociais. 50\% dos recursos deliberados pelo COP foram destinados para as áreas de educação (20\%), saúde (14\%), habitação (10\%) e assistência social (6\%).

Somando os recursos destinados para as áreas de Educação, Saúde, Habitação e Assistência Social, aos recursos destinados a obras de infra-estrutura, como pavimentação, temos, praticamente, 80\% dos destinados à atenção de necessidades básicas da população de Campinas, o que demonstra um nítido processo de inversão de prioridades.

Não podemos deixar de destacar os $4 \%$ dos recursos destinados ao tema gestão. Como já foi dito, encontramos um aparelho de Estado destroçado, os investimentos são necessários para a reconstrução democrática do aparelho de Estado.

No quadro 04 temos os dados dos recursos que foram investidos nas regiões da cidade. Estes dados nos permitem perceber a distribuição espacial dos investimentos definidos no OP. Chama atenção os montantes investidos nos regiões mais carentes, um nítido processo de democratização espacial dos investimentos e de inversão de prioridades.

Segundo os dados as três regiões que mais perceberam investimentos são as das Administrações Regionais 13, 12 e 6. Juntas foram contempladas com cerca de R\$ 50 milhões, ou 47\% dos recursos empenhados. Segundo o senso de 2000, as mesmas regiões, juntas, respondem por 32\% da população da cidade, ou 310.417 moradores. Não podemos de destacar também que estas regiões são as mais carentes da cidade. O Mapa da Vulnerabilidade Social de Campinas foi feito a partir das 83 UTB’s (Unidades Territorial Básica) da cidade. Para cada uma destas UTB’s foram calculadas as variáveis que compõem seus índices de vulnerabilidade. As 08 UTB's com maior índice de vulnerabilidade estão localizadas nas três regiões que mais foram atendidas pelo OP. É 
interessante perceber ainda que as três regiões mobilizaram mais de $30 \%$ das pessoas que participaram e ajudaram a indicar prioridades de investimentos para a cidade de Campinas.

\section{Quadro 04 - Comprometimento dos recursos do OP por região}

\begin{tabular}{|l|cr|}
\hline Região & \multicolumn{2}{|c|}{ Valor Comprometido } \\
\hline Administração Regional 1 & $\mathrm{R} \$$ & $3.390 .811,26$ \\
\hline Administração Regional 2 & $\mathrm{R} \$$ & $1.610 .835,47$ \\
\hline Administração Regional 3 & $\mathrm{R} \$$ & $1.654 .058,05$ \\
\hline Administração Regional 4 & $\mathrm{R} \$$ & $1.423 .578,63$ \\
\hline Administração Regional 5 & $\mathrm{R} \$$ & $2.079 .417,21$ \\
\hline Administração Regional 6 & $\mathrm{R} \$$ & $15.333 .571,24$ \\
\hline Administração Regional 7 & $\mathrm{R} \$$ & $5.958 .817,63$ \\
\hline Administração Regional 8 & $\mathrm{R} \$$ & $4.283 .165,48$ \\
\hline Administração Regional 9 & $\mathrm{R} \$$ & $3.025 .347,67$ \\
\hline Administração Regional 10 & $\mathrm{R} \$$ & $8.131 .156,37$ \\
\hline Administração Regional 11 & $\mathrm{R} \$$ & $2.799 .999,26$ \\
\hline Administração Regional 12 & $\mathrm{R} \$$ & $12.839 .200,60$ \\
\hline Administração Regional 13 & $\mathrm{R} \$$ & $21.816 .826,13$ \\
\hline Administração Regional 14 & $\mathrm{R} \$$ & $2.959 .552,70$ \\
\hline Distrito de Barão Geraldo & $\mathrm{R} \$$ & $4.833 .372,69$ \\
\hline Distrito de Joaquim Egidio & $\mathrm{R} \$$ & $653.858,36$ \\
\hline Distrito de Nova Aparecida & $\mathrm{R} \$$ & $8.451 .365,81$ \\
\hline Distrito de Sousas & $\mathrm{R} \$$ & $5.560 .299,30$ \\
\hline Total & $\mathrm{R} \$$ & $106.805 .233,86$ \\
\hline
\end{tabular}

Fonte: Coordenadoria Especial da Participação Popular e do Orçamento Participativo PMC; set/2004

* Neste montante não estão contidos os investimentos feitos nas demandas de habitação.

\section{5) APONTAMENTOS DA EXPERIÊNCIA}

Com certeza as dinâmicas e os resultados apresentados são frutos da nossa experiência. Pois se Avritzer (2003) frisa que promover a expansão do OP ou repetir a experiência porto-alegrense em outros ambientes não é tarefa simples de realizar, nossa experiência ocorreu num território com gritantes desigualdades sócio-espaciais, com atores sociais fortemente organizados e sob um Governo marcado pelo assassinato do seu Prefeito. 
Não por acaso, portanto, tivemos um governo onde a independência na formulação das políticas setoriais e na atuação das áreas foram significativas. Ou seja, as áreas trabalharam, na quase totalidade dos casos, de forma autônoma em relação ao conjunto do governo, ou a partir do estágio de construção coletiva entre os atores envolvidos com o debate do setor. O que nos deu uma característica particular. Como exemplo de construção autônoma e democrática temos a saúde, situação que não a exclui de contradições geradas com a dinâmica dada a partir da implantação do OP. Esta questão nos ajuda entender os limites da organização setorial do Estado e as dificuldades para uma intervenção planejada territorialmente, que busque superar a lógica dos setores e rompa com “a totalidade do diabo" (SANTOS; 1979).

Na dinâmica da sociedade civil, as Temáticas da Cidadania e de Desenvolvimento Econômico, envolveram questões e provocaram debates interessantes entre as necessidades e os representantes dos seguimentos participantes das respectivas temáticas, com as demais necessidades e representações regionais ou dos outros temas. Ainda na sociedade civil, percebe-se nas suas diferentes dinâmicas de articulação com o Estado, resquícios da relação que esta estabeleceu com o Estado, ou seja, uma relação autoritária - por parte da burocracia - e, pior, setorializada. Como conseqüência temos excelentes militantes em alguns temas, que muitas vezes não conhecem os problemas do território onde mora. Como conseqüência enfrentam dificuldades de articulação política com outros atores e demandas.

Os caminhos a serem trilhados ainda são muitos, mas acho que foi possível apresentar alguns que foram percorridos pelo OP Campinas, assim como algumas dificuldades e desafios enfrentados e a serem superados se mantida a disposição de democratizarmos nossa cidade. 


\begin{abstract}
The article looks to present Orçamento Participativo's experience - OP Campinas, lifting subjects related to the relationship of OP with the dynamics of the state and of the civil society. The proposal is to discourse about the democratization of the state and of the civil society discussing with variables that along the experience. And still to contribute with the debate of the democratization of our territory.
\end{abstract}

KEY-WORDS: Democracy; State and Civil Society

\title{
REFERÊNCIAS BIBLIOGRÁFICAS
}

AVRITZER, L. O Orçamento Participativo e a teoria democrática: um balanço critico. In: A Inovação democrática no Brasil: $O$ orçamento participativo, São Paulo: Cortez, (Org) AVRITZER, Leonardo e NAVARRO, Zanser, 2003

BORON, Atílio Os ‘novos Leviatãs' e a polis democrática: neoliberalismo, decomposição estatal e decadência da democracia na América Latina”. In: SADES, Emir e GENTIL, Pablo Pós Neoliberalismo II: Que Estado para Que Democracia. 4ª Edição Petrópolis, RJ: Editora Vozes, 2004.

DAGNINO, Evelina. Sociedade Civil, Espaços Públicos e a Construção Democrática no Brasil: Limites e Possibilidades. In: DAGNINO, Evelina (Org.) Sociedade Civil e Espaços Públicos no Brasil. São Paulo: Paz e Terra, 2002, pp. 279-301.

GENRO, Tarso. Orçamento Participativo: a experiência de Porto Alegre. São Paulo: Perseu Abramo, 1997.

GRUPO DE ESTUDOS SOBRE A CONSTRUÇÃO DEMOCRÁTICA. Idéias, Revistas do Instituto de Filosofia e Ciências Humanas, Campinas, ano 5 (2)/ 6 (1), 1999.

PONT, Raul. Democracia, Participação, Cidadania: uma visão de esquerda. Porto alegre: Palmarinda, 2000.

PREFEITURA MUNICIPAL DE CAMPINAS. Mapa da Vulnerabilidade Social; Campinas: PMC, 2004.

SANTOS, Milton. Economia Espacial: críticas e alternativas.Tradução Maria Irene Q F Szmrecsányi. São Paulo: HUCITEC, 1979.

\begin{tabular}{llllll}
\hline Serviço Social \& Saúde & Campinas & v. 4 & n. 4 & p. 1-156 & Maio 2005 \\
\hline
\end{tabular}


SAES, Décio O Conceito de Estado Burguês, in: SAES, Décio. Estado e Democracia: Ensaios Teóricos, Campinas: IFCH / UNICAMP, 1994.

THERBORN, Göran. As teorias do Estado e seus desafios no final do século. In: SADES, Emir e GENTIL, Pablo. Pós Neoliberalismo II: Que Estado para Que Democracia. $4^{\mathrm{a}}$ Edição Petrópolis, RJ: Editora Vozes, 2004. 
